\title{
Simulation of bypass electric water pump to reduce the engine warm-up time
}

\author{
R.I Abdul Jalal, M.A. Mohd Yusoff, H.M. Abid Hasan and M.N Yahya \\ Automotive Engineering Section, Malaysia France Institute, Universiti Kuala Lumpur, 43650 Bandar Baru Bangi, Malaysia
}

\begin{abstract}
There are several strategies have been developed in the automotive cooling system to improve engine thermal management. Basically, these designs use controllable actuators and mechatronic components such as electric water pump, controllable thermostat, and controllable electric fan to improve engine temperature control on most operating ranges. Most of the strategies are complicated and costly. This paper introduced a different approach to improve coolant temperature warm-up during cold start. The new strategy was by promoting a higher coolant flow rate inside the engine block by just installing an electric water pump in the bypass hose. The new approach's cold start performance was studied using GT-SUITE on a transient model, complete with finite-element of engine block design, lubrication system, components friction model, engine with combustion model and vehicle system. The proposed strategy clearly showed faster coolant temperature increase (18 seconds faster compared to the conventional cooling system). The strategy not only increase the coolant temperature faster, but also increases the oil temperature faster, lower Friction Mean Effective Pressure (FMEP), and lower fuel consumption at certain condition during the warm-up period.
\end{abstract}

ARTICLE HISTORY

Received: $06^{\text {th }}$ July 2020

Revised: $27^{\text {th }}$ Apr 2021

Accepted: $02^{\text {nd }}$ June 2021

\section{KEYWORDS}

Cooling system;

engine thermal

management;

engine warm-up;

electric water pump.

\section{INTRODUCTION}

Many researches have been done to reduce the fuel consumption of an automotive vehicle, especially under cold start state operating conditions where the highest fuel consumption occurs accompanied by highest emissions [1-5]. Among them, the cooling system is spotlighted because it has a great effect on fuel economy. During the cold start, the coolant fluid and lubricant oil are cold, therefore engines suffer higher friction and less efficient combustion resulting in higher fuel consumption and higher harmful emissions [6-8]. The viscosity of lubricant oil affects mechanical friction whereby at low temperature, the lubricant has high viscosity leading to increasing friction loss $[9,10]$. Coolant temperature needs to be high during cold start to increase engine temperature until it achieves normal operating temperature.

The conventional cooling system uses a mechanical water pump to maintain the circulation of the coolant through the system. The pump is a centrifugal type in a tight metal casing and driven by the crank of the engine through a belt. The pump speed is in proportion to only engine speed and not to desired engine thermal. Therefore, the pump is not providing an optimal output control in different engine operating condition. Besides that, the mechanical pump could cause unnecessary parasitic losses because driven by engine speed [11, 12].

Fuel consumption penalty occurs during cold start since the temperature of the engine is not an ideal work. Once engine starts, the engine control unit (ECU) will collect temperature reading from engine coolant temperature sensor whereby this data will be used to adjust fuel injection and ignition timing. Thus, engine speed will be higher at the cold start operating condition to allow more fuel enters the combustion chamber. Therefore, the warm-up period must be as fast as possible to reduce fuel consumption.

There are several designs have been developed in the automotive cooling system to improve engine thermal efficiency. Basically, these designs use controllable actuators and mechatronic components such as electric water pump, controllable thermostat, and controllable electric fan to improve engine temperature control on most operating ranges [12-16]. Overall, the design would be more complex but there are pros and cons on these designs. Therefore, this work was focused on an engine thermal management technique that has minimal changes to the existing component and increase the coolant temperature faster to reduce the engine warm-up time.

To establish the minimal changes goal, a bypass electric water pump was introduced. The propose concept was just required a minimum modification the to the existing cooling system. An electric water pump was added to the bypass pipe as shown in Figure 1 on the right. The bypass pipe in most engines is made from rubber which would make the installation of the bypass electric water pump easy by just splitting the rubber hose and install the electric pump.

The bypass pump will increase the flow back to the engine during the warm-up phase. This is an approach that is totally different compared to other engine thermal management with electric water pump. All other thermal management will try to have a very low coolant flow rate during warm-up via lowering the electric water pump speed [12-14]. This project was to demonstrate of the high coolant flow rate technique via bypass pump during the engine warm-up phase. 

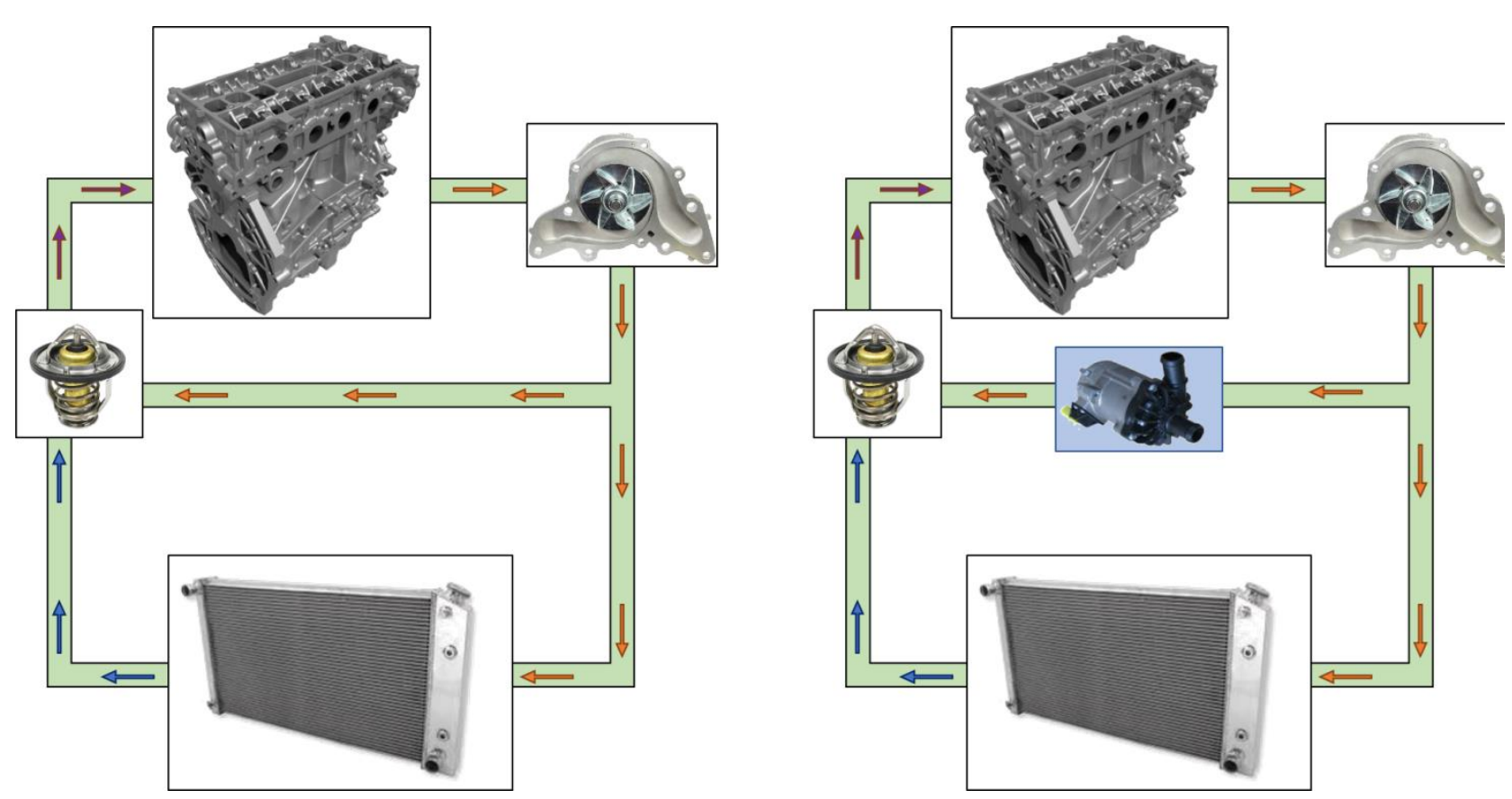

Figure 1. (Left) conventional cooling system layout. (Right) electric water pump added to the bypass pipe

\section{METHODOLOGY}

\section{Transient Warm-up Model Setup}

The work was done using a model template provided in the GT-SUITE with some modification to suit the purpose of the work. This was due to the project focused on showing the overall understanding and analyze the potential phenomenon before implementing it on an actual engine. The model for this research used was a transient warm-up model consist of a vehicle model, engine model, cooling system, lubrication system, engine controller and friction model (Figure 2). All models mentioned were required to ensure all components related to the coolant's heat energy flow and temperature distribution changes were considered.

The engine model was a 3.2L Diesel turbocharged engine with 'EngCylCoombDIWiebe' as its combustion model. The combustion model imposes the combustion burn rate for direct-injection, compression-ignition engines using a threeterm Wiebe function: premix, main and tail. 'WoschniGT' was used as the in-cylinder heat transfer model. The heat transfer will be calculated using a formula which closely emulates the classical Woschni correlation without swirl. The difference lies in the treatment of heat transfer coefficients during the period when the valves are open, where the heat transfer is increased by inflow velocities through the intake valves and also by backflow through the exhaust valves [17].

The in-cylinder wall temperature was modelled using an available module in the GT-SUTIE, 'EngCylStrucCond' module. It was used to model the cylinder structure of an engine using a finite element representation of the cylinder liner, piston, port, valve and head. The structure was connected to the cooling system, lubrication system and the mass material of the engine block and head to simulate the total engine heat transfer and simulate the in-cylinder temperature distribution.

The friction model consists of valvetrain, piston, con rod, main bearing and accessory components' friction load. The friction model was based on friction maps and linked to the engine speed, indicated mean effective pressure (IMEP) and oil temperature. The piston friction model was modified to model the piston friction based on coolant temperature rather than the oil temperature as proposed by Fisher (2000) [18]. This was to ensure that the heat generated from the friction was also considered. 


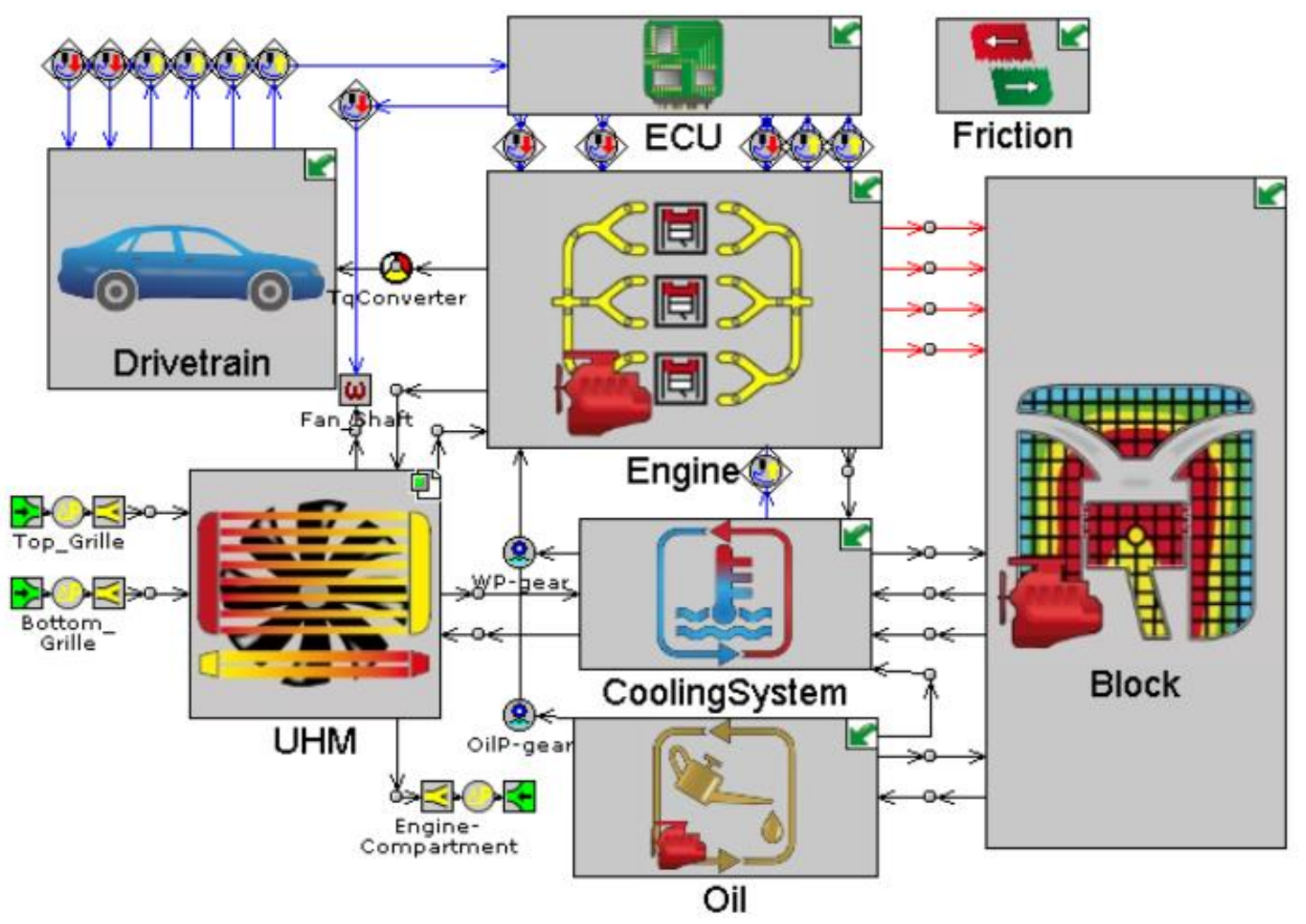

Figure 2. Overall model for transient warm-up analysis

\section{Cooling System Layout}

The cooling system model of the engine has been changed to suit the work objectives. An additional water pump was added to the model as shown in the red dashed line in Figure 3. The additional pump represents the bypass electric water pump at the bypass pipe which is the proposed concept for this project that was to increase the flow rate during the warmup phase. The electric water pump speed was controlled independently to create a different coolant flow rate flow rate in the bypass pipe. The engine warm-up time was observed and compared to the coolant flow rate in the bypass pipe. The mechanical water pump speed was linked to the engine speed.

An oil cooler has been added to the cooling system and the lubrication system. This was to ensure that the overall model was comparable with a common cooling system setup of a turbocharged engine. The oil cooler material heat transfer rate data were based on Palmgren and Wallborg (2015). The oil cooler is a common practice to help the oil temperature increase faster during the warm-up phase, which also has big effects on the engine friction [20-23].

This simulation model was to represent a common heat transfer model for a complete vehicle thermal management. The result of this work might be different for different type of cooling system model or different type of structure. This was because different type of structure can give different heat transfer pattern. 


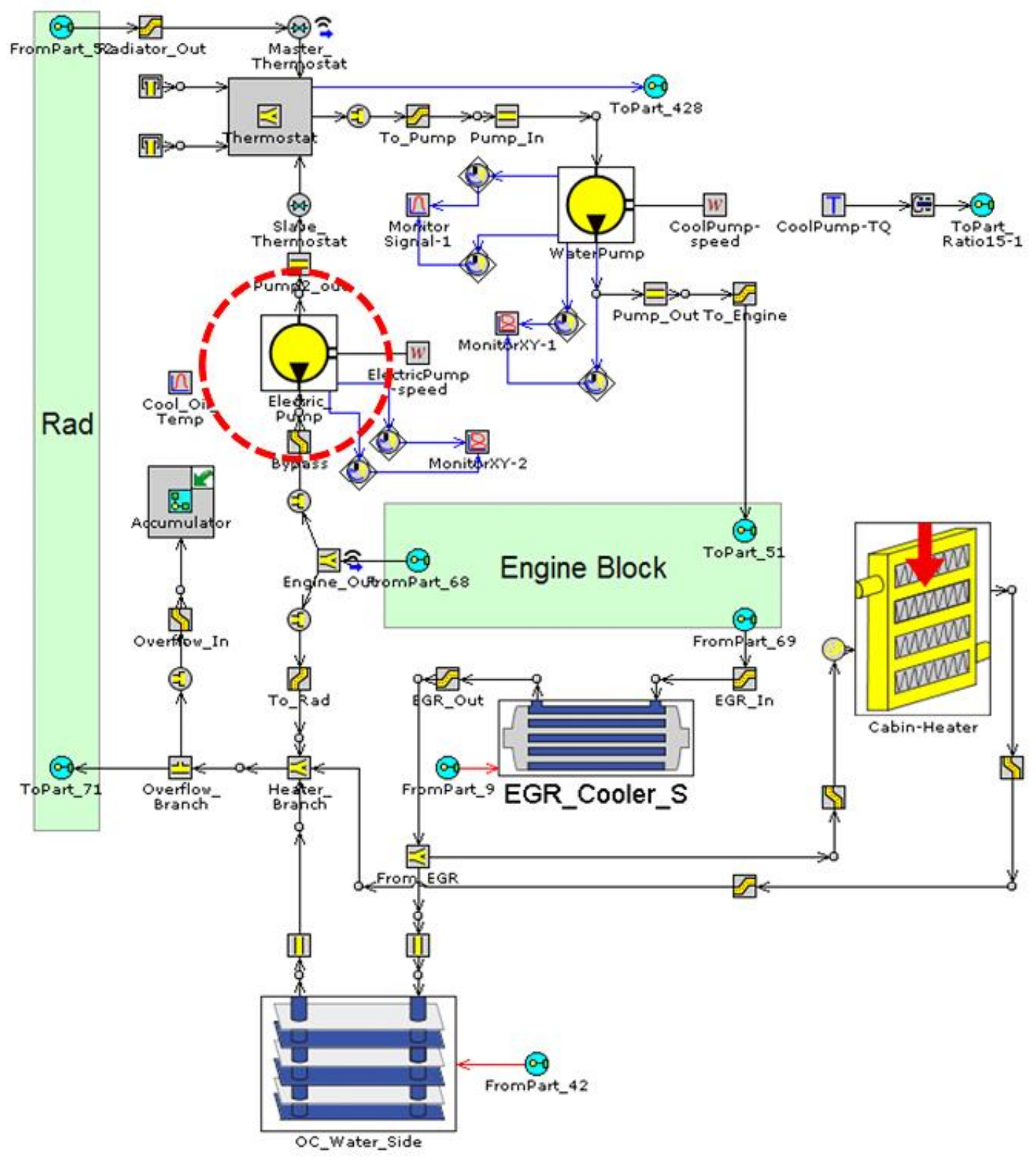

Figure 3. The cooling system model and the red dashed line represent the electrical water pump at the bypass pipe

\section{Series Pump Orientation}

The cooling system model used two water pumps are used (the bypass electric water pump and the engine mechanical water pump as shown in Figure 3), and it was orientated in a series arrangement during the thermostat is in full close position. This arrangement was a common arrangement in civil and mining industries to produce higher flow rate in high head pressure system [24]. This is also the method to reduce cost by using a combination of smaller pumps rather than a single larger pump. This technique was used in this work to increase the coolant flow rate to improve the heat transfer to excape from the engine to the coolant. This was the proposed concept to increase the coolant temperature faster than conventional coolant system (single mechanical water pump).

A modification was made to both water pump map to ensure the cooling system was able to run in a series pumps arrangement. The modification was to allow the pumps, especially the mechanical water pump to run in negative pressure (pressure inlet larger than outlet). An extrapolation was made to the pumps at the negative pressure region and at the negative flow rate region (back flow region) as shown in Figure 4. The pump parameter was also changed from 'explicit' to 'conservative implicit' pump model to make it more robust but slower to converge. 


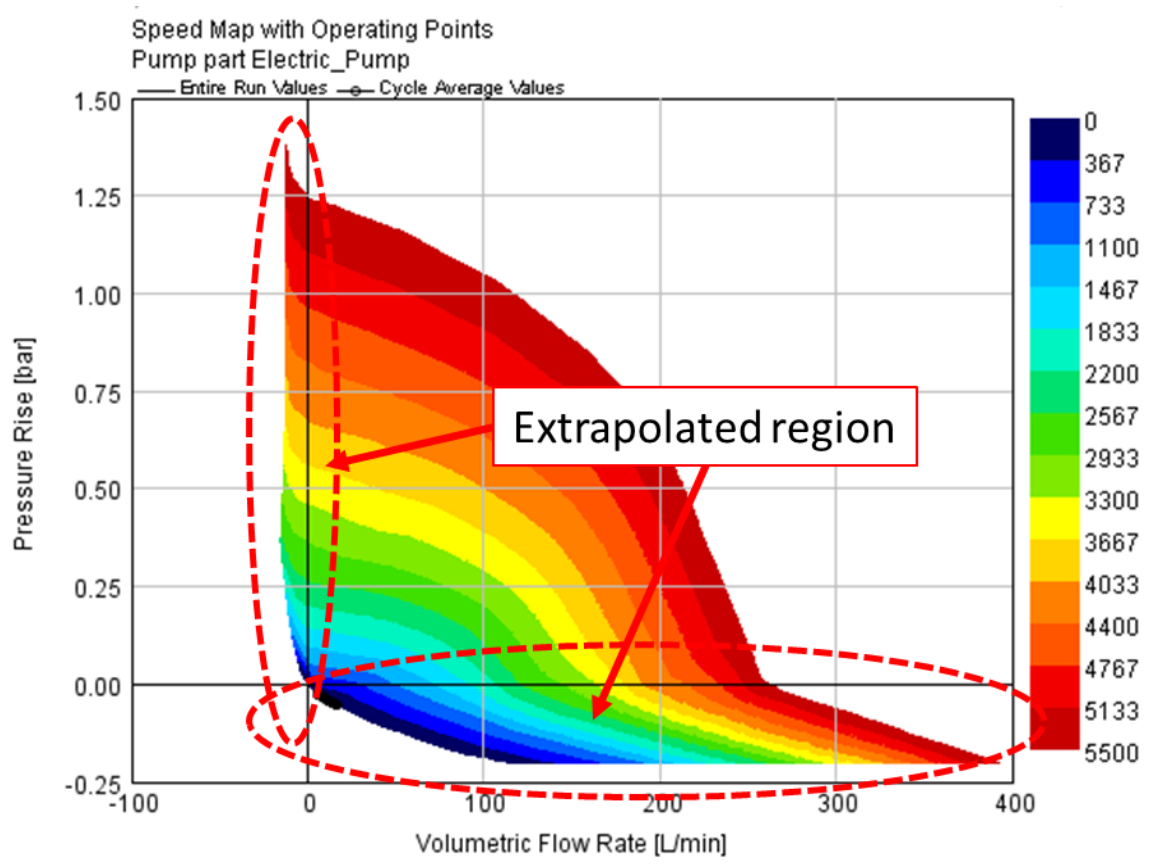

Figure 4. Pump map with extrapolated region

\section{Simulation Case Setup}

The engine was maintained at idling, at $800 \mathrm{rpm}$ and about 0.5 bar BMEP (very minimum load), which common a situation during the engine warm up. The fluids for the cooling system model were the 50/50 glycol-water mix (Case Study 1). The coolant temperature and the other components were set at $26.85^{\circ} \mathrm{C}$ as the initial temperature. The bypass electric pump speed was set at 0 to $5500 \mathrm{rpm}$ with $1000 \mathrm{rpm}$ interval, while the mechanical water pump speed was set as per engine speed. The cabin heater heat transfer was set at zero to limit the scope of work.

Additional simulations were also done in different situations to analyze the cooling system with the bypass electric water pump's warm up behavior. The vehicle speed was also varied at $30 \mathrm{kmh}$ and 100kmh (Case Study 2). This is to see the engine warm-up at higher heat from the higher engine load. Although it is quite impossible to achieve at the real situation, The adiabatic conditions were also considered to predict the full potential of the proposed strategy (Case Study $3)$.

\section{RESULTS AND DISCUSSION}

\section{Case Study 1: Warm-up During Idling}

The coolant flow rate increased as the bypass electric water pump speed increased (Figure 5). However, the flow rate was lower compared to the conventional cooling system when the bypass electric water pump was not running. This was due to the non-moving electric water pump only create a flow restriction to the system rather than assisting the mechanical water pump. The flow rate reduction was reduced $43.8 \%$ compared to the conventional cooling system. This was also a good finding as having the bypass electric water pump can produce a very low coolant flow rate if required in some situation. The flow rate of the system started to produce higher coolant flow rate than the conventional system when the bypass electric water pump ran at 1000rpm. At 5500rpm (maximum speed of the bypass electric water pump) the flow rate increased up to $319 \%$ compared to the conventional coolant flow rate. A sudden flow rate drop was observed after 400 seconds, this was due to some of the additional coolant flow starts to divert to the radiator when the thermostat started to open. Another interesting observation was that the coolant flow rate has drop significantly which the maximum bypass electrical water pump speed only gained $145 \%$ (from $319 \%$ ). However, there was also possibility that the coolant flow rate changes will behave differently if using different coolant system layout. The flow rate could have lower drop if the flow restriction was higher in the radiator flow circuit. The other observations were the coolant temperature, thermostat lift, oil temperature, engine friction changes and the engine fuel consumption. 


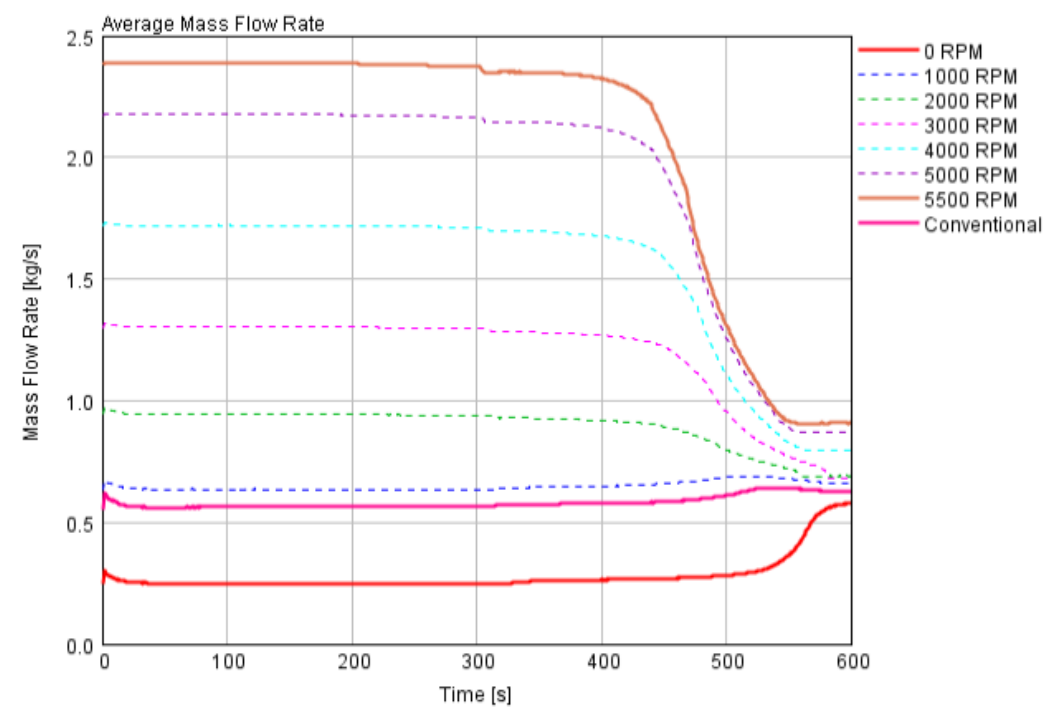

Figure 5. Electric water pump speed influence on the coolant mass flow rate during idling warm-up

\section{Coolant Temperature}

The result showed that a higher coolant flow rate increased the coolant temperature faster (Figure 6 and Figure 7) which was one of the objectives of the strategy. The $5500 \mathrm{rpm}$ (maximum electric pump speed) achieved $82^{\circ} \mathrm{C}$ faster compared to others. The maximum pump speed reached $82^{\circ} \mathrm{C}$ faster by 18 seconds compared to the conventional cooling system. The $5500 \mathrm{rpm}$ was $0.32 \%$ higher than the conventional cooling system at 250 seconds. This temperature increase was slight increased but significant to the warm-up time reduction. The temperature trend changes after the thermostat starts to open. A higher bypass electric pump speeds created a sudden drop to the coolant temperature after the thermostat valve opened and allow coolant to flow to the radiator. The temperature then increased back with a slight temperature overshoot at 570s. The lower speed just has the coolant temperature gradually increase before it starts to stabilize. This strategy can possibly improve the cabin heating performance during engine warm-up as the coolant carried more heat energy (higher coolant temperature with high flow rate) to the cabin.

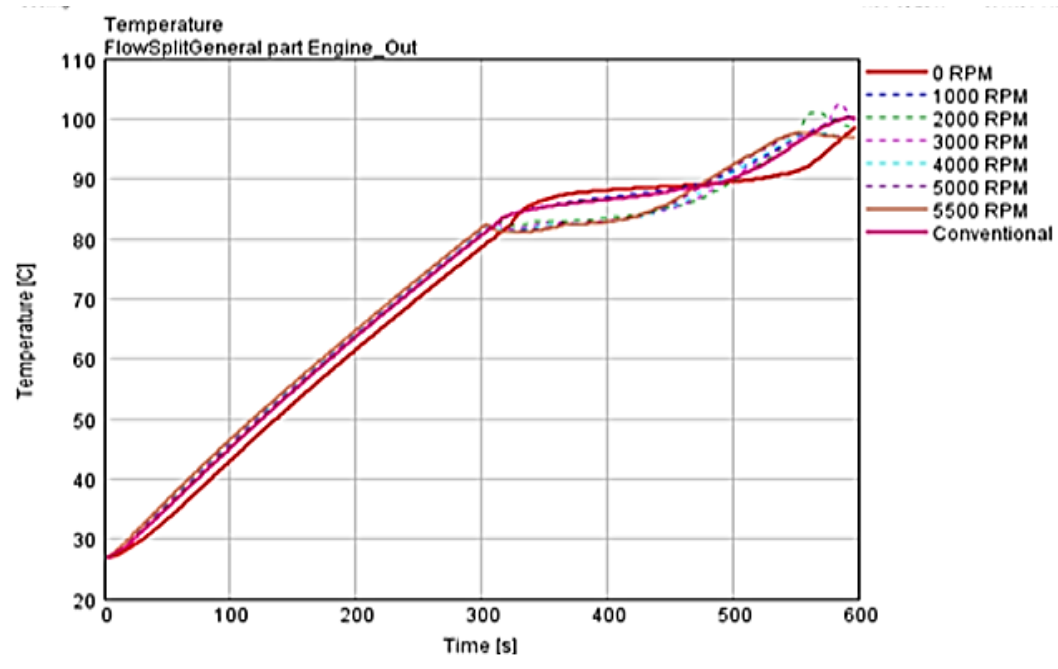

Figure 6. Electric water pump speed influence on the coolant temperature increase during idling warm-up

Two important observations can be noticed from the coolant flow rate in the radiator: backflow in the radiator when the bypass pump in high speed; and improve radiator flow rate when the bypass pump was running very slow. The backflow in the radiator happened when the thermostat valve started to open (Figure 8). The higher the bypass electric pump speed, the more undershoot of the backflow occurred. The backflow in the radiator could reached $618 \%$ higher flow rate compared to the conventional cooling system but in a reverse direction (at 500 seconds in Figure 8). This could possibility affect the radiator performance to remove the excessive heat generated by the engine. There can be an argument that the pipe position in actual condition (as the simulation model does not consider the height of the pipe inlet and outlet position) will potentially reduce the flow rate, but still, it should not be signification. In this case (other cooling system layout can cause different outcome), the reason for backflow was the back pressure generated by the bypass electric water pump was. High speed of the bypass pump will create a high-pressure head which lead to the flow go to the radiator in 
reverse direction as the radiator in the model has low overall flow resistance compared to the engine water jacket. Therefore, applying the bypass pump should only be activated before the thermostat valve is open to avoid the backflow.

In contrary to the first observation, the bypass pump increased the coolant flow rate in the radiator when it was not running (Figure 8). This can clearly be seen at the 600 seconds where the flow rate increased $22 \%$ compared to the conventional cooling system. The reason was the bypass electric pump create a flow restriction in the bypass pipe, thus more coolant flow to the radiator then the bypass pipe. This means that the heat from the engine can be remove more by having the bypass electric water pump in the bypass pipe. This shows that the bypass electric water pump was very effective to increase the coolant temperature during the engine warm-up (runs in high speed) and also very effective to ensure more coolant flow to the radiator (pump not running), thus more heat can be removed.

\section{Thermostat Lift}

The thermostat opening time can be used as an indicator to confirm that the coolant has reached near the target operating temperature. The faster the coolant temperature increased, the faster the coolant heat up the thermostat's wax and the faster it opened the thermostat valve. Figure 9 shows the thermostat valve position during the idling warm-up for every bypass electric water pump speed. The result shows that $5500 \mathrm{rpm}$ opened the earliest at 303s, this is $3.19 \%$ faster than a conventional cooling system (Figure 10). This could be slightly faster if the thermal heat capacitance were not included in the model. The thermostat opened 3.82\% slower when the electric water pump speed was 0rpm.

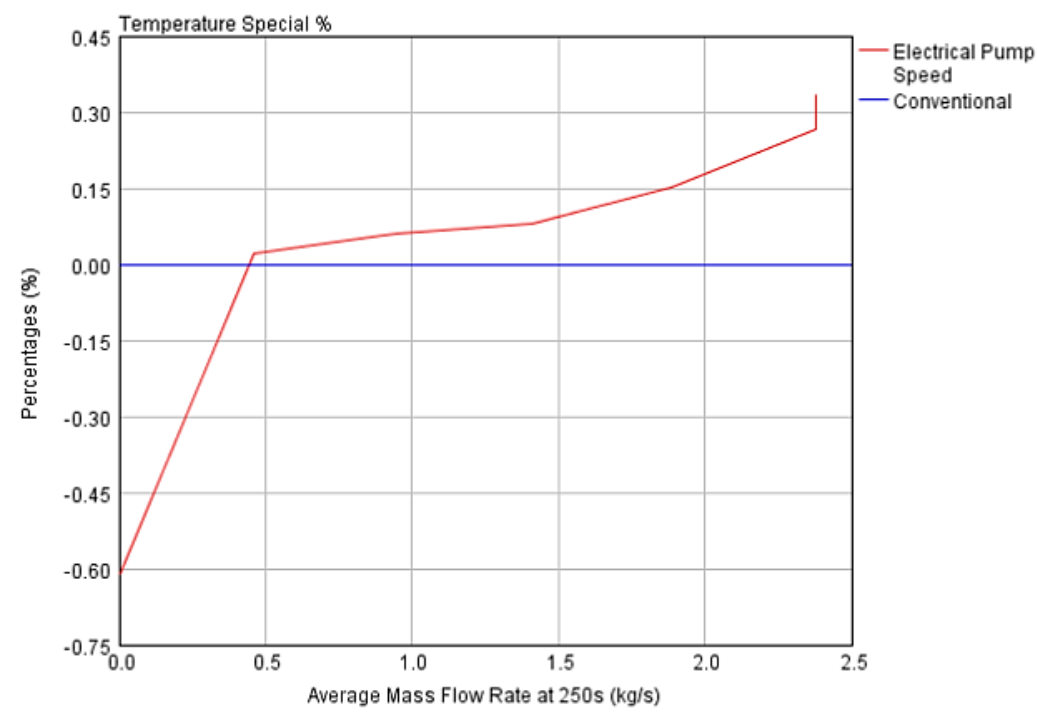

Figure 7. Coolant mass flow rate influence on the temperature increment in percentages at 250s during idling warm-up

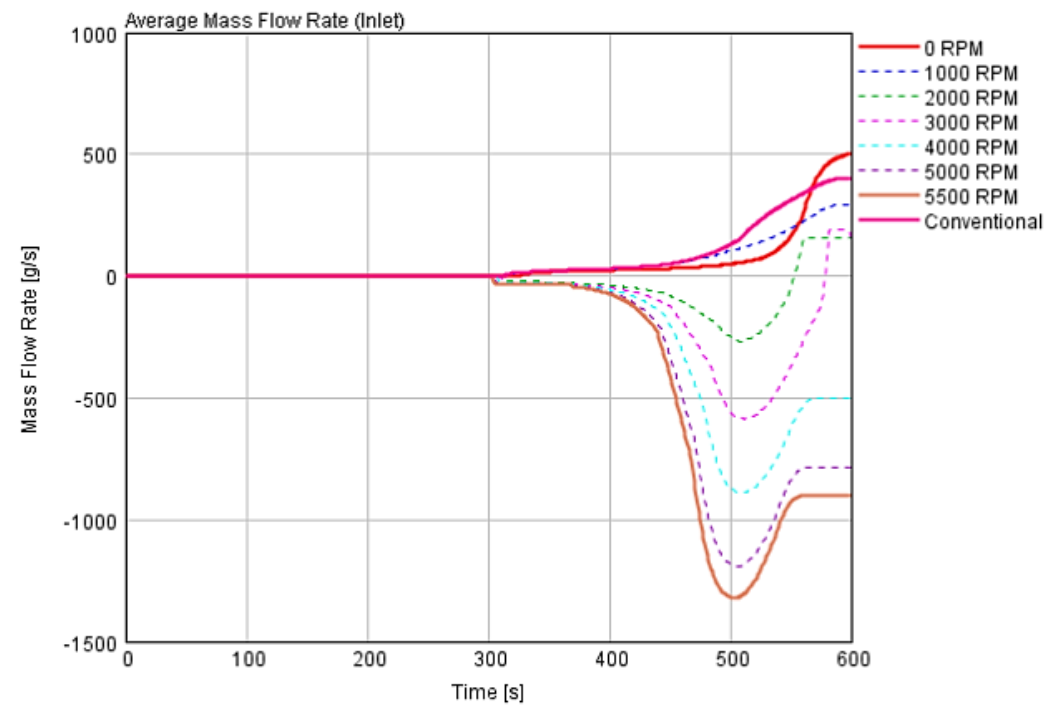

Figure 8. Mass flow rate at radiator outlet during engine warm-up 


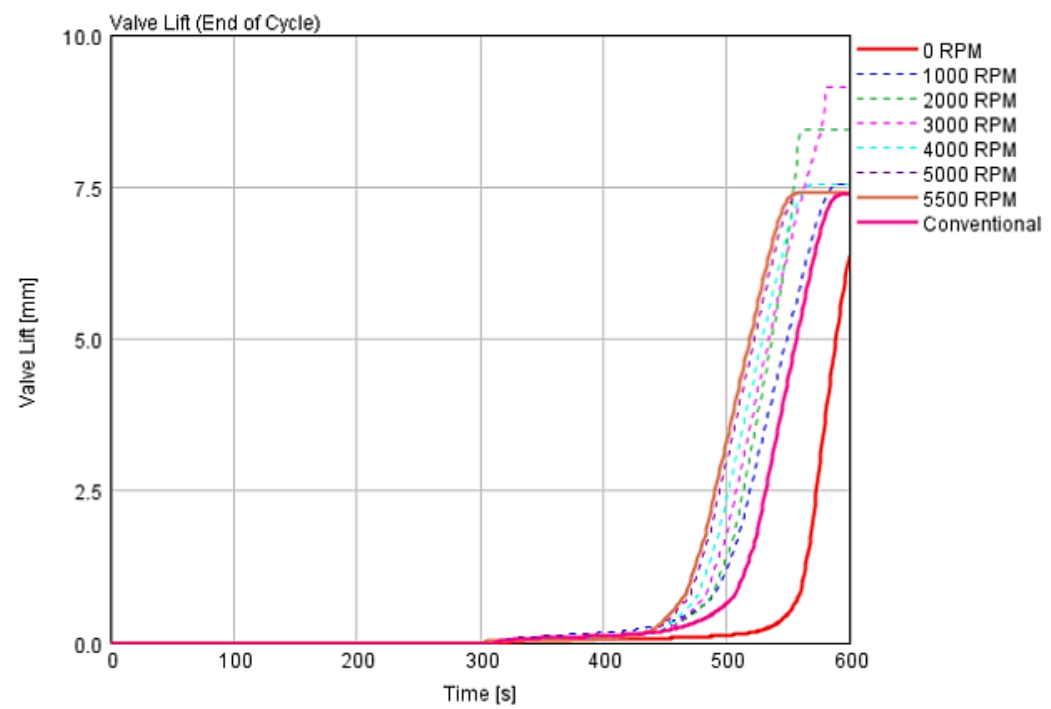

Figure 9. The thermostat valve opening during idling warm-up

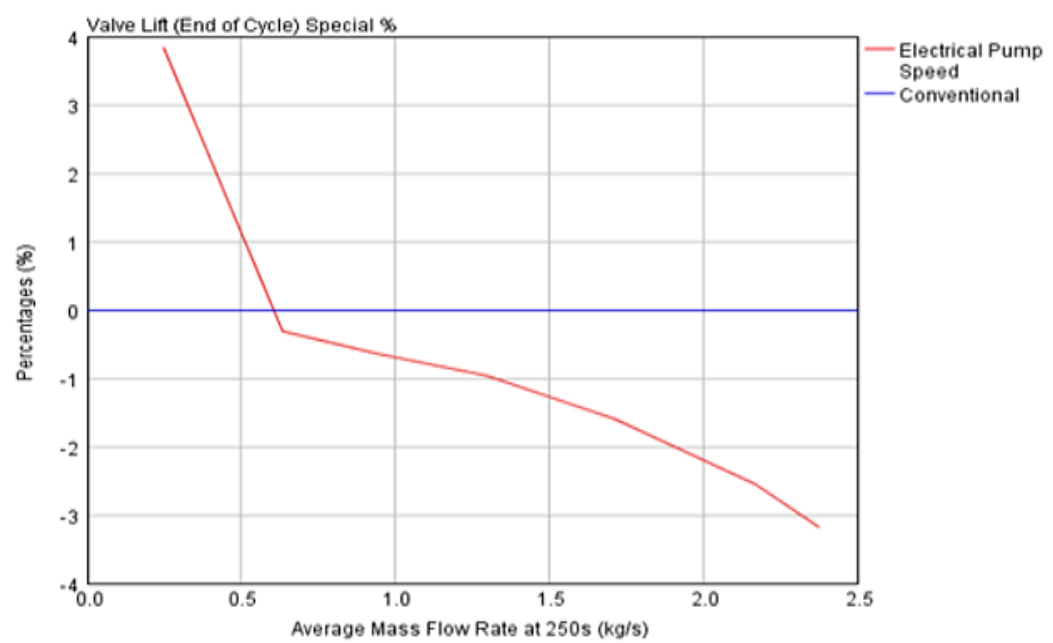

Figure 10. The thermostat valve starts to open time in percentage for every electric water pump mass flow rate compared to the conventional cooling system

\section{Oil Temperature, Engine Friction and Fuel Consumption}

Other important results during the warm-up were the oil temperature, friction, and the fuel consumption. The engine oil temperature was also very important parameter during the engine warm-up. The engine oil needed to reach the optimum operation temperature to ensure the oil viscosity was suitable for the engine operation. High oil viscosity will cause high internal engine component friction which can leads to bad fuel consumption and emission [25]. The bypass electric water pump does improve the oil temperature warm-up as shown in Figure 11. The oil temperature increased $7.94 \%$ higher than the conventional cooling system's oil temperature. This was due to the high temperature coolant heat up the engine oil via the oil cooler.

The bypass electric water pump strategy has also showed that it can reduce the engine internal friction during the engine warm-up (Figure 12). Based on the model setup, the reason of the friction reduction was due to the higher oil temperature and coolant temperature. The oil temperature affected the camshaft friction, crankshaft friction and the oil pump friction. The coolant temperature affected the engine cylinder wall friction which was consistence with previous studies [26, 27]. The friction reduced $0.15 \%$ at the maximum bypass electric water pump speed increase.

Figure 13 shows the comparison of the fuel consumed (from 0 to 250 seconds of the engine warm-up) compared to the coolant flow rate generated by the bypass electric water pump. The result shows that, the drawback of the strategy was the fuel consumption showed slightly increased with the higher coolant mass flow rate. The increase of the fuel consumption was due to the combustion model runs at a lower engine wall temperature. 


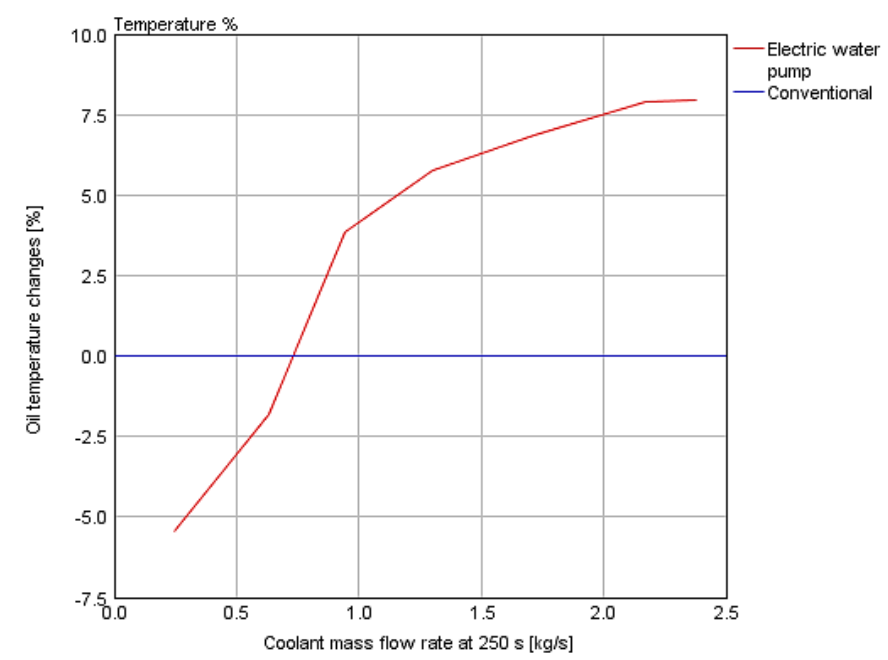

Figure 11. Percentages of oil sump temperature increase with different coolant flow rate compared to the conventional cooling system at $250 \mathrm{~s}$ during idling warm-up

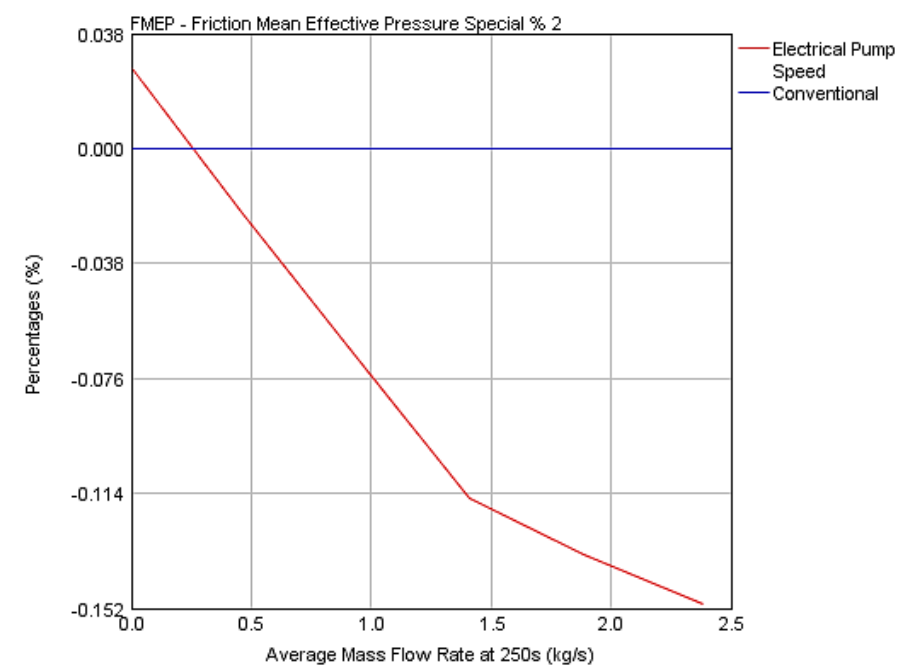

Figure 12. Percentages of FMEP changes compared to the conventional cooling system on various coolant mass flow rates

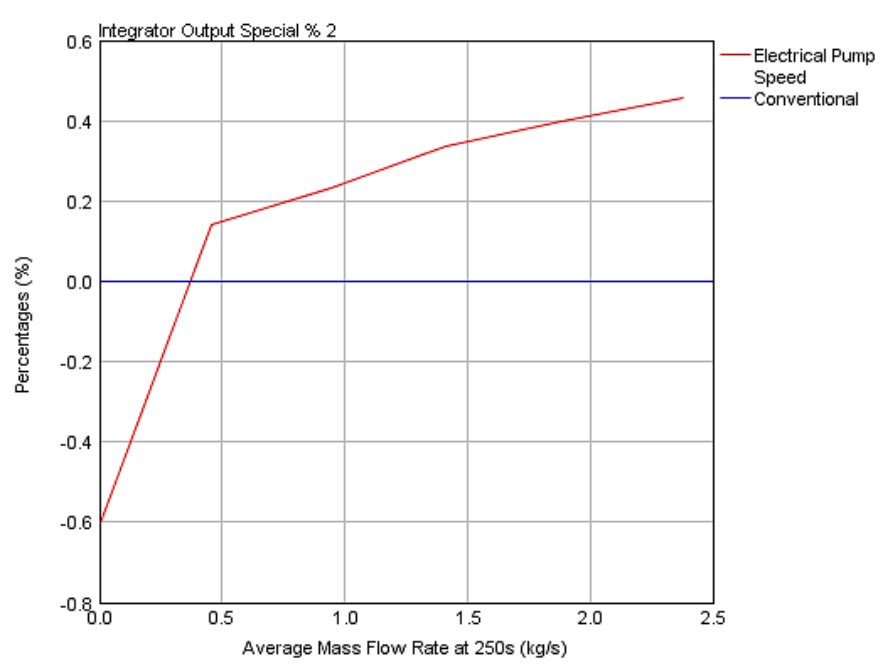

Figure 13. Percentage of fuel consumed (from 0 to 250 seconds) change compared to the conventional cooling system 


\section{Case Study 2: Warm-up at $30 \mathrm{~km} / \mathrm{h}$ and $100 \mathrm{~km} / \mathrm{h}$}

The work was extended to the warm-up process at high heat from high engine load. This was done by the vehicle running at $30 \mathrm{~km} / \mathrm{h}$ and $100 \mathrm{~km} / \mathrm{h}$. This will increase the engine combustion heat transfer to the coolant but with higher mechanical water pump speed. With the mechanical water pump speed increased, the bypass electric water pump had not giving much different to the cooling system's flow rate. The additional flow rate generated from the maximum bypass electric water pump has dropped to $50.2 \%$ and $8.2 \%$ for $30 \mathrm{~km} / \mathrm{h}$ and $100 \mathrm{~km} / \mathrm{h}$ warm-up (Figure 14). This is relatively small compared to the bypass electric water pump generated additional coolant flow rate (362\%). However, the coolant temperature increases faster with higher vehicle speeds when equip with the bypass electric water pump. This can be clearly seen in the Figure 15 as the opening time reduces to $3.63 \%$ and $5.68 \%$ for $30 \mathrm{~km} / \mathrm{h}$ and $100 \mathrm{~km} / \mathrm{h}(3.19 \%$ compared to warm-up during idling). The fuel consumption also showing a good sign as it reduces to $0.34 \%$ and $0.28 \%$ for $30 \mathrm{~km} / \mathrm{h}$ and $100 \mathrm{~km} / \mathrm{h}$ (Figure 16Error! Reference source not found.Error! Reference source not found.). This shows that the bypass electric water pump's fuel consumption gain can be reduced by higher heat generated by the engine. This was potentially from the better combustion quality and friction reduction. This also means that there were also potential to reduce the bad emission especially during the warm-up phase. The bypass pump also can reduce further the thermostat opening time with the higher heat generated by the engine.
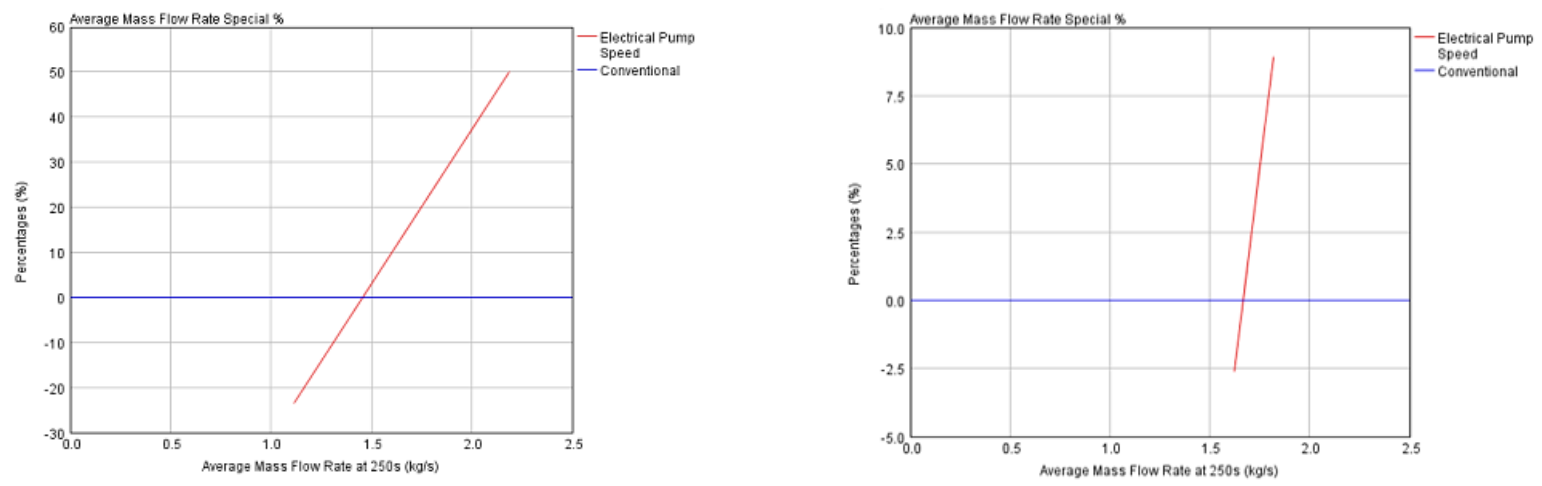

Figure 14. Coolant mass flow rate changes in percentage for $30 \mathrm{~km} / \mathrm{h}$ (left) and $100 \mathrm{~km} / \mathrm{h}$ (right)
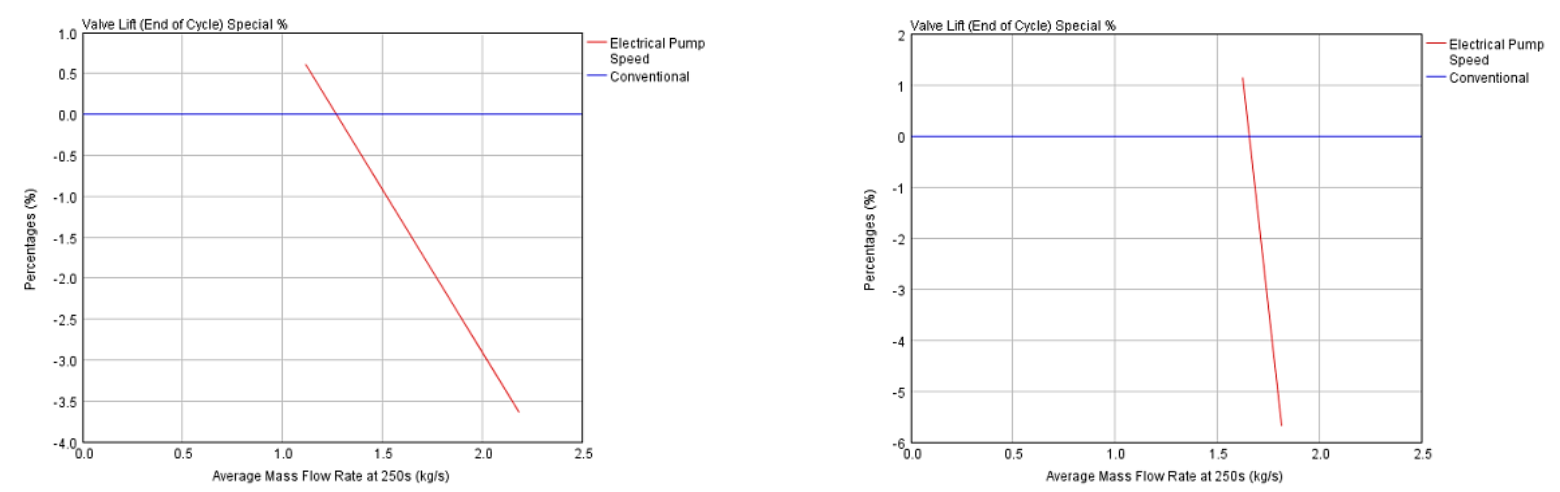

Figure 15. Thermostat opening time changes in percentage compared to the conventional cooling system at (left) $30 \mathrm{~km} / \mathrm{h}$ and (right) $100 \mathrm{~km} / \mathrm{h}$
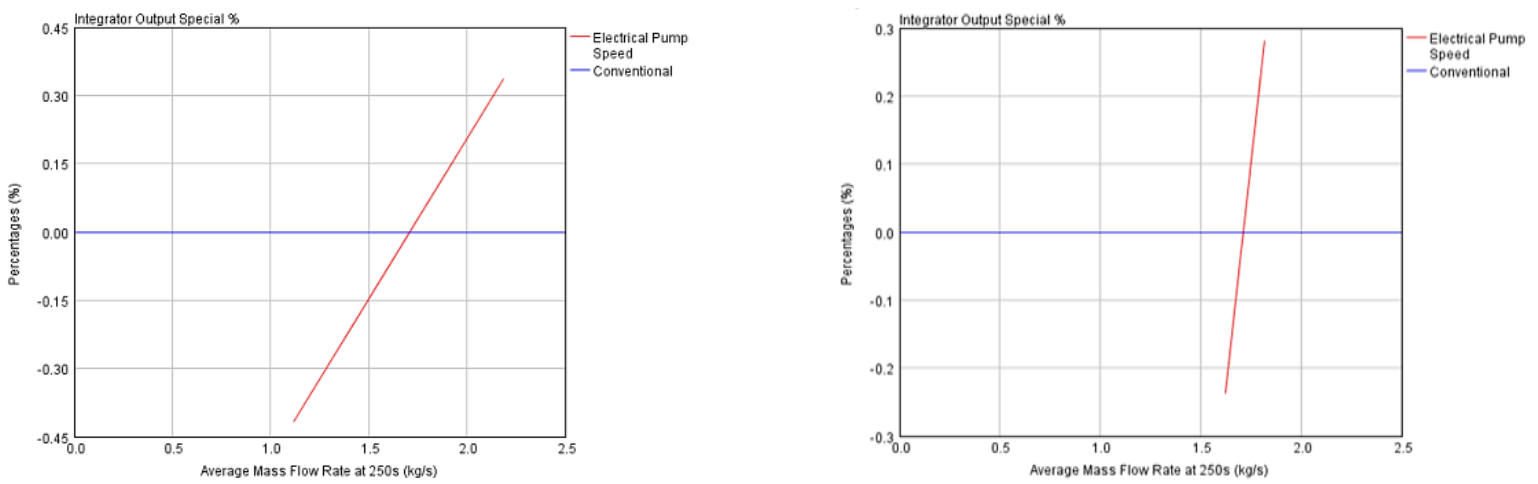

Figure 16. Fuel consumed (from 0 to 250 seconds) changes in percentage compared to the conventional cooling system at (left) $30 \mathrm{~km} / \mathrm{h}$ and (right) $100 \mathrm{~km} / \mathrm{h}$ 


\section{Case Study 3: Warm-up with Adiabatic Cooling System}

One of the issues of this technique was the bypass water pump could increase the heat loss to the environment from the pipe walls, hoses and engine block wall as the model also calculated this heat loss. The higher the coolant flow rate caused more heat loss from these components to the environment during the engine warm-up. Changing it to an adiabatic modelling will stop these heat losses to the environment and only retain the heat within the cooling system (except at the radiator) during the warm-up phase. This adiabatic model was done to evaluate the full theoretical potential when having the bypass electric water pump in the engine cooling system.

Based on the result under the adiabatic model, the coolant temperature increase showed clearly that the adiabatic model gives advantage to the bypass electric water pump. It increased the coolant temperature further $2.58 \%$ compared without adiabatic model (Figure 17). The model also shows an advantage in fuel consumed reduction as it shows lower fuel consumption compared to the conventional cooling system (Figure 18). These means that despite the minimum modification required to add the bypass electric water pump, it required a big modification to reach its full potential. It required full thermal insulator for all engine component that the heat can escape to the environment (example: coolant hose, thermostat pipe, engine block, cylinder head and oil pan). This required a lot of changes and high cost.

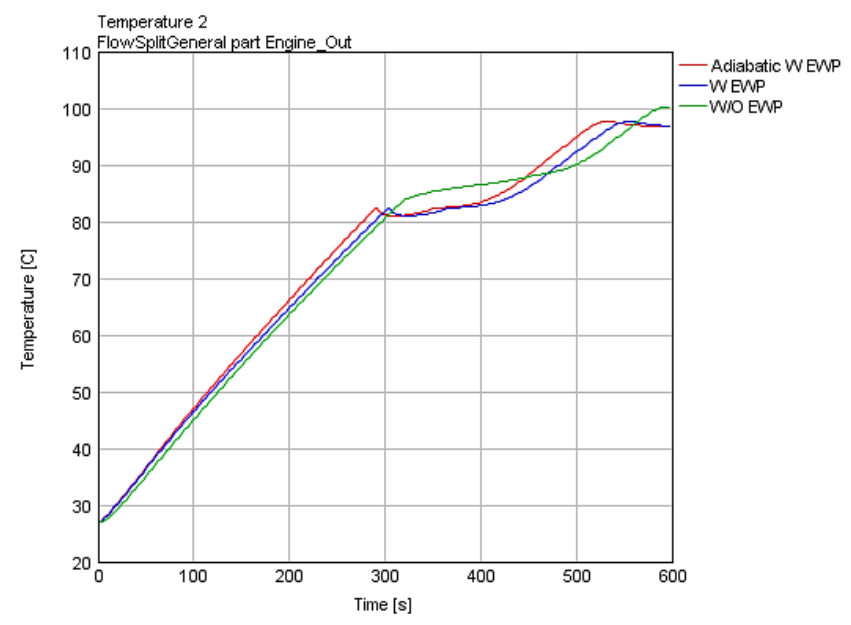

Figure 17. Coolant temperature increase during warm-up between conventional cooling system, bypass electric motor at $5500 \mathrm{rpm}$ and adiabatic model with the $5500 \mathrm{rpm}$ bypass pump

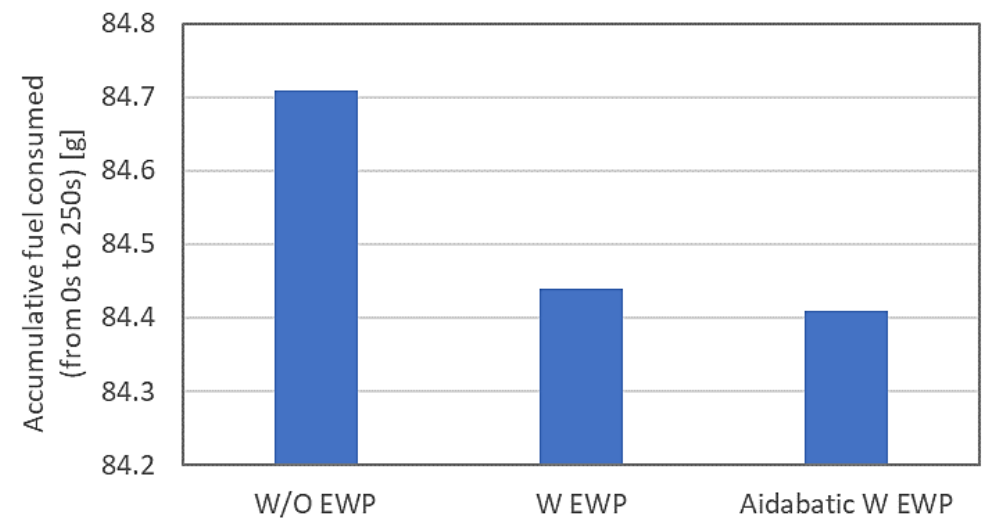

Figure 18. Fuel consumd accumulation (from 0 to 250 seconds) during warm-up for the conventional cooling system, bypass electric pump at $5500 \mathrm{rpm}$ and adiabatic model with the bypass pump

\section{CONCLUSIONS}

This research proposed a new technique to reduce the warm-up time by applying a minor modification to the engine cooling system. The proposed technique was only to increase the coolant flow rate by installing a bypass electric pump in the bypass hose.

This clearly showed that this technique can increase the coolant temperature and reduce the warm-up time to $3.19 \%$ with maximum bypass pump speed compared to the conventional cooling system. The coolant temperature was $0.32 \%$ higher than the conventional cooling system. This temperature increase was slight increased but significant to the warmup time reduction. The technique can also improve the cabin heating as the coolant temperature and flow rate were higher via the bypass electric water pump. The technique also reduced $0.15 \%$ the friction (FMEP) compared to the conventional 
cooling system as it can increase the oil temperature faster. However, the downside was that the bypass electric water pump will cause a slight increase in the consumed fuel $(0.45 \%)$ as the high coolant flow rate caused more heat losses in the combustion to the environment from the pipe wall, hoses and engine wall. The adiabatic model has proved that without the heat losses the bypass electric water pump can reduce the fuel consumption. This technique was also tested in at higher warm-up heat from higher engine load (via moving vehicle at $30 \mathrm{~km} / \mathrm{h}$ and $100 \mathrm{~km} / \mathrm{h}$ ). The effect of bypass pump improves further with higher higher heat generated. the warm-up time improved $5.68 \%$ at $100 \mathrm{~km} / \mathrm{h}$.

\section{REFERENCES}

[1] A. Boretti and S. Watkins, "Reduced warm-up and recovery of the exhaust and coolant heat with a single loop turbo steamer Integrated with the engine architecture in a hybrid electric vehicle," SAE Tech. Pap., Nov. 2013.

[2] J. Lahuerta and S. Samuel, "Numerical simulation of warm-up characteristics and thermal management of a GDI engine," SAE Tech. Pap., Apr. 2013.

[3] F. Will and A. Boretti, "A new method to warm up lubricating oil to improve the fuel efficiency during cold start," SAE Int. J. Engines, vol. 4, no. 1, pp. 2011-01-0318, 2011.

[4] R. Burke et al., "Systems approach to the improvement of engine warm-up behaviour," Proc. Inst. Mech. Eng. Part D J. Automob. Eng., vol. 225, no. 2, pp. 190-205, Feb. 2011.

[5] T. Kamimoto and M. Bae, "High combustion temperature for the reduction of particulate in diesel engines," SAE Tech. Pap., 1988.

[6] P. J. Shayler and C. Belton, "In-cylinder fuel behaviour and exhaust emissions during the cold operation of a spark ignition engine," Proc. Inst. Mech. Eng. Part D J. Automob. Eng., vol. 213, no. 2, pp. 161-174, Jan. 1999.

[7] P G Boulter, "Environmental traffic management : A review of factors affecting cold start emissions," 1997.

[8] D. Di Battista, D. Vittorini, F. Fatigati, and R. Cipollone, "Technical review of opportunities to reduce the warm-up time of lubricant oil in a light-duty diesel engine," AIP Conf. Proc., vol. 2191, no. December, 2019.

[9] D. Singh, J. D. Fieldhouse, A. K. Jain, M. R. Tyagi, and S. K. Singal, "Investigating the effect of operating variables and engine lubricant viscosity on engine friction- A DOE approach," SAE Tech. Pap., Oct. 2011.

[10] S. Park, Y. Cho, K. Sung, and N. Han, "The effect of viscosity and friction modifier on fuel economy and the relationship between fuel economy and friction," SAE Tech. Pap., vol. 2, no. 2, pp. 72-80, Nov. 2009.

[11] T. Castiglione, G. Franzè, A. Algieri, P. Morrone, and S. Bova, "ICE thermal management: A model predictive control approach for CO2 reduction," SAE Tech. Pap., vol. 2017-Septe, 2017.

[12] B. K. Roy, "Control strategies for advanced thermal management system in IC engine -An overview," no. May 2015, 2013.

[13] T. Castiglione, F. Pizzonia, and S. Bova, "A novel cooling system control strategy for internal combustion engines," SAE Tech. Pap., vol. 9, no. 2, pp. 2016-01-0226, Apr. 2016.

[14] R. I. Abdul-Jalal, "Engine thermal management with model predictive control," Loughborough University, 2016.

[15] T. Castiglione, P. Morrone, L. Falbo, D. Perrone, and S. Bova, "Application of a model-based controller for improving internal combustion engines fuel economy," Energies, vol. 13, no. 5, p. 1148, Mar. 2020.

[16] L. Feng, J. Wikander, and Z. Li, "Fuel minimization of the electric engine cooling system with active grille shutter by iterative quadratic programming," IEEE Trans. Veh. Technol., vol. 69, no. 3, pp. 2621-2635, 2020.

[17] Gamma Technologies, GTISE 7.2 Help (English), Version7.2. 2010.

[18] G. D. Fischer, "Expertenmodell zur berechnung der reibungsverluste von ottomotoren,” PhD thesis, Technischen Universität Darmstadt zur, 2000.

[19] J. Palmgren and M. H. Wallborg, "Improving engine oil cooler performance: For future vehicle applications," Uppsala Universitet, 2015.

[20] Y. Inaguma and N. Yoshida, "Mathematical analysis of influence of oil temperature on efficiencies in hydraulic pumps for automatic transmissions," SAE Tech. Pap., Apr. 2013.

[21] H. Kim, J. Shon, and K. Lee, "A study of fuel economy and exhaust emission according to engine coolant and oil temperature," J. Therm. Sci. Technol., vol. 8, no. 1, pp. 255-268, 2013.

[22] R. Mufti and M. Priest, "Effect of cylinder pressure on engine valve-train friction under motored and fired conditions," Proc. Inst. Mech. Eng. Part J J. Eng. Tribol., vol. 226, no. 4, pp. 306-314, Jan. 2012.

[23] S. R. Nattrass and A. Davenport, "Application of a split lubrication gasoline engine to the screening and understanding of friction modifier behaviour," SAE Tech. Pap., vol. 5, no. 1, pp. 511-522, Aug. 2011.

[24] M. E. Qazizada and E. Pivarčiová, "Reliability of parallel and serial centrifugal pumps for dewatering in mining process," in Acta Montanistica Slovaca, 2018, vol. 23, no. 2, pp. 141-152.

[25] J. Macek, D. Fuente, and M. Emrich, “A simple physical model of ICE mechanical losses,” SAE Tech. Pap., Apr. 2011.

[26] T. Matsutani, T. Nakada, Y. Shinpo, and M. Hatano, "Water jacket spacer for improvement of cylinder bore temperature distribution," SAE Tech. Pap., vol. 2005, no. 724, Apr. 2005.

[27] C. Sethu, M. E. Leustek, S. V Bohac, Z. S. Filipi, and D. N. Assanis, “An investigation in measuring crank angle resolved incylinder engine friction using instantaneous IMEP method,” SAE Tech. Pap., no. 724, pp. 776-790, Oct. 2007. 